\title{
数学基礎論の伝統と新しい手法: 逆数学
}

\section{1 はじめに}

数学基礎論は, 数学を展開するためにどのような公 理系が十分かという問題について, 19 世紀末くらいか ら数多くの成果を築いてきた。しかし, 数学全般を基 礎付けるような完全な公理系が存在しないことを 1931 年に Gödel が示した後は, 数学(の理論や命題)に どのような公理が真に必要か, あるいはどのような公 理系では不十分かという問題へ関心をシフトしていっ た。具体的な進展は, 1963 年のP. Cohenの結果に よって始まった。彼は, 連続体仮説と選択公理が $\mathbf{Z F}$ 集 合論の公理から導けないことを証明した。1977 年に は, Paris と Harrington が, Peano 算術では証明で きない有限組合せ論の真なる命題を発見した。その後 も, 公理系からの独立命題に関する研究はたくさんあ るが, たとえばベクトル空間の基底の存在定理に選択 公理が真に必要であることが示されたのも漸く 1984 年のことである (Blassによる)。また, 巨大基数の存 在など ZF 集合論の枠を大きくはみ出す公理の研究も 1980 年代から盛んになった。このような研究は, 堅固 な数学をあえて不安定な基礎の上に乗せるという意味 合いから,「反基礎論」と呼ばれることもある（[11]に おける Smoryñskiの記事を参照)。

本論のテーマである「逆数学」は, 伝統的基礎論の 形態を継承しつつ, 精神的には「反基礎論」の立場に たつ現代基礎論の研究プログラムである。数学の大部 分が丁度うまく収まる箱として, D. Hilbert が導入し た公理系に 2 階算術の体系 $\boldsymbol{Z}_{2}$ がある（[3]）。そして， 伝統的基礎論の流れにおいては， $Z_{2}$ の無矛盾性を示す ことを旗印とした研究が今日まで続いている。他方, 「逆数学」の目的は, 箱の疵を検査することではなく, 箱を叨いて中の数学の様子を調べることにある。

70 年代半ば, H. Friedman ([2]) は, $\boldsymbol{Z}_{2}$ の弱い部

\footnotetext{
* 東北大学大学院理学研究科
}

分体系 $\mathbf{R C A}_{0}$ とそこから独立ないくつかの集合存在 公理について次のような現象に気付いた：

数学の主な定理は, $\mathbf{R C A}_{0}$ で証明できてしまうか, 4 つほどの存在公理のどれかと同値であることが

$\mathbf{R C A}_{0}$ で証明できる。 80 年代に入ると, さらに多くの定理についてこの現象 が確認され, S. Simpson らによってシステマチックな 研究が進むとともに, 逆数学 (reverse mathematics) と呼ばれる研究プログラムに発展した（[6]）。

このように必要十分な公理の強さによって, 数学の 定理を分類してみると, 数学史の流れや, 異なる理論 間の感覚的な類似性がうまく捉えられるというのがこ のプログラムの売り物である。たとえば，中間值の定 理より実数の連続性(例：Weierstraßの上限に関する 公理）の方が強い存在公理を必要とすることが証明さ れる。普通の教科書では実数の連続性を仮定して中間 值の定理が証明されるが，歴史的には連続性の公理の 方があとから発見されており，逆数学の結果は数学史 の流れがより高度な集合論を求める方向に進んだこと を物語る。

「逆数学」の研究の中でとくに注目されるようになっ たのが, 弱 König の補題である。「有限分岐の無限木が 無限の道を持つ」というのが一般の König の補題で, その主張を 0,1 の 2 進列からなる木に制限したものを 弱 König の補題と呼ぶ。非常に多くの定理が弱 König の補題と同值になることがわかっている。その一方, 弱 König の補題に基づく公理系 $\mathbf{W K L} \mathrm{K}_{0}$ の無矛盾性は, Hilbert の有限の立場の形式化である PRA の無矛盾 性に還元できることが証明されており, Hilbert のプ ログラムとの関係において「逆数学」の研究が重視さ れている。

本論では, 前半で「逆数学」の概要を述べ, 後半で は筆者自身がこの数年に携わった仕事を紹介する。 1990 年半ばまでの「逆数学」のサーベイには, [8], [9] がある。すでに品切れであるがこの分野の標準的な教 
科書に [6] がある。さらに，ロジック一般の教科書を 兼ねてのこの分野への入門書として, 拙著 $[10],[12]$, [13］もご参考にしていただければ幸いである。

\section{Hilbert のプログラム}

Hilbert は, 数学の論証のほとんどが第 1 階論理 （first-order logic）において形式化できること，そし て数学の諸概念は自然数と簡単な集合の概念に還元で きることに着目し，自然数とその集合を扱う第 1 階理 論（もしくは，自然数の第 2 階理論）の性質（とくに 無矛盾性）を明らかにすれば，数学のかなりの部分の 明晰性が得られると考えた。そして，そのような公理 系として 2 階算術の体系 $\boldsymbol{Z}_{2}$ を考案し, また, 有限個の 記号を有限的に操作することだけを許す立場として有 限の立場（finitism）を提唱した。

有限の立場に立って, $Z_{2}$ がおかしな言明を導出しな いこと，つまり $Z_{2}$ で証明されるどのような有限的言 明 (等式, 不等式など) も有限の立場で正しいこと $\left(\boldsymbol{Z}_{2}\right.$ の有限還元性 (finitistic reduction)) に対する確証が ほしい。そのためには，ある一つの偽なる有限的言明 $0=1$ が $\boldsymbol{Z}_{2}$ で導出されないこと(無矛盾性)を有限の立 場で示せば十分であり, さらに無矛盾性の問題は決定 問題 (Entscheidungsproblem) に帰着できることがわ かった。そこで, Hilbertは,

“決定問題が数理論理学の中心的問題である”

と明言している $([1]) 。$

しかし, Hilbert の企図は Gödel の不完全性定理 （1931）により修正を余儀なくされた。Gödel の結果は, その論文の題名『... 形式的に決定不能な命題について』 が語るように, 決定問題が絶望的に難しいことを示し ている。その結果を一般化し, 第 1 階論理の決定問題 に否定的な決着をつけたのは, A. Church (1936)とA.

Turing（1937）である。

彼らは決定可能性（=計算可能性＝再㷌性）とは何 かを厳密に定義し, 決定不可能な問題の存在を示すと ともに, 不可能性さの度合いを調べる研究分野 (再帰 理論, 計算可能性理論)を開拓した。それは 70 年頃ま でには数理論理学の中心的分野(の一つ)になるが, 数 学の基礎から離れる方向のみに急成長したので, Hilbert の時代を知る人 S. MacLane ら）から非難を受け ることもあった ([11])。H. Friedman, S. Simpson ら に代表される「逆数学」の主要な研究者たちは, もと もと再帰理論の研究グループの出である。彼らは,
Hilbert の企図とは対極にある非決定性の研究の中で 生まれた高度技術を応用して, Hilbert のプログラム の現代的な意味を再考しているといえるだろう。

\section{Peano 算術と 2 階算術}

Peano の 5 つの公理は, 現代的な意味での公理系で はない。Fregeや Russell の研究を下敷きに, 第 1 階の 自然数論を最初に正確に定義したのは Hilbertであ り，それを今日の形に整えたのは Gödel である。むか しは Hilbert 算術という呼び名もあったが，今日では 大概 Peano 算術と呼ばれている。

Peano 算術 PA は第 1 階の自然数論であり, 厳密に は $\mathcal{L}_{1}=\{+, \cdot, 0,1,<\}$ を言語とし，等号を含む第 1 階論理の上で，以下の 8 つの基本公理及び数学的帰納 法の公理図式 Ind で構成される ([12] 参照)。

$$
\begin{array}{ll}
-(x+1=0), & x+1=y+1 \rightarrow x=y, \\
x+0=x, & x+(y+1)=(x+y)+1, \\
x \cdot 0=0, & x \cdot(y+1)=x \cdot y+x, \\
\neg(x<0), & x<y+1 \leftrightarrow x<y \vee x=y,
\end{array}
$$

Ind : $\varphi(0) \wedge \forall x(\varphi(x) \rightarrow \varphi(x+1)) \rightarrow \forall x \varphi(x)$.

さて, 以前はPA の論理を第 2 階論理に拡張したも のを 2 階 Peano 算術と呼んでいたが, 第 2 階論理は公 理化が難しいので, 最近はそのような定式化はあまり 行われない。第 2 階論理の述語変数の代わりに自然数 の集合に関する変数を導入して, 第 1 階の理論として 形式化したものを 2 階算術 (second order arithmetic) もしくは解析 (analysis) と呼ぶのが一般的である。自 然数 $n$ は単元集合 $\{n\}$ として扱えばよいので, 自然数 の集合だけを対象とする純粋な 1 階理論にもなるが, ここでは自然数上を動く変数と集合変数を別々に用意 し，いわゆる 2 領域の 1 階理論として扱う。

2 階算術の言語 $\mathcal{L}_{2}$ を $\mathcal{L}_{1} \cup\{\epsilon\}$ とする。変数は, 数 変数 $x, y, \ldots$ と集合変数 $X, Y, \ldots$ の 2 種類を用いる。 等号 $=$ は, 数に関するものを原始記号とし, 集合に関 する $X=Y$ は $\forall x(x \in X \leftrightarrow x \in Y)$ の略記とする。原子 式 $s=t, s<t, s \in X$ 加命題結合記号と有界量化記号 $\forall x<t, \exists x<t$ だけを使って作られる論理式を有界な 論理式と呼び,その全体を $\sum_{0}^{0}\left(=\Pi_{0}^{0}\right)$ で表す。ここで, $\forall x<t$ は $\forall x(x<t \rightarrow \cdots), \exists x<t$ は $\exists x(x<t \wedge \cdots)$ の 省略形で, $t$ は $x$ を含まない項とする。各自然数 $i$ につ いて, $\varphi$ が $\sum_{i}^{0}$ 論理式のとき $\forall x_{1} \cdots \forall x_{k} \varphi$ を $\prod_{i+1}^{0}$ 論 理式, $\varphi$ が $\prod_{i}^{0}$ 論理式のとき $\exists x_{1} \cdots \exists x_{k} \varphi$ を $\sum_{i+1}^{0}$ 論理 
式という。これらを合わせて算術的論理式と呼び，そ の全体を $\sum_{0}^{1}\left(=\prod_{0}^{1}\right)$ で表す。さらに, 各自然数 $i$ につ いて, $\varphi$ が $\sum_{i}^{1}$ 論理式のとき $\forall X_{1} \cdots \forall X_{k} \varphi$ を $\prod_{i+1}^{1}$ 論 理式, $\varphi$ が $\prod_{i}^{1}$ 論理式のとき $\exists X_{1} \cdots \exists X_{k} \varphi$ を $\sum_{i+1}^{1}$ 論 理式という。

2 階算術の体系 $\boldsymbol{Z}_{2}$ は, PA の 8 つの基本公理と, 任 意の $\mathcal{L}_{2}$-論理式 $\varphi(x)$ に関する数学的帰納法 Ind と 下記の内包公理図式

$$
\text { CA : } \exists X \forall x(x \in X \leftrightarrow \varphi(x))
$$

からなる。CAの $\varphi(x)$ を論理式のクラス $\Gamma に$ 属する ものに制限してできる $\boldsymbol{Z}_{2}$ の部分体系を $\Gamma-\mathbf{C A}$ で表 す。さらに Ind にある種の制限を与えたものを $\Gamma-\mathbf{C A}_{0}$ と表す。

\section{4 逆数学の概要}

逆数学の議論の基礎になる体系 $\mathbf{R C A}_{0}$ は， $\boldsymbol{Z}_{2}$ の帰 納法 Ind $の$ 論理式 $\varphi(x)$ を $\sum_{1}^{0}$ 論理式に, 内包公理 $\mathbf{C A}$ の $\varphi(x) を \Delta_{1}^{0}$ 論理式 ( $\prod_{1}^{0}$ 論理式と同值になる $\sum_{1}^{0}$ 論理 式）に制限したものである。算術の標準モデルの上で $\Delta_{1}^{0}$ 論理式で定義される集合の族は再帰的集合の族で あるから，これを再帰的内包公理の体系と呼ぶ。荒つ ほくいえば， $\mathbf{R C A}_{0}$ で展開される数学は計算機が扱え る範囲の数学である。この体系で証明できる $\prod_{1}^{0}$ 文は, 有限の立場の形式化とされる PRA でも証明でき，有 限還元性が成り立つ。

$\mathbf{R C A}_{0}$ における数学の展開について述べる。自然数 の対や有限列を一つの自然数でコードするような議論 は原始再帰的であり，この体系内で自由にできる。し たがって, 整数 $\mathbb{Z} は \mathbb{N} \times \mathbb{N}$ の上で, 有理数 Q は $\mathbb{Z} \times$ $(\mathbb{Z}-\{0\})$ の上で, 適当な同值類を作り代表元を選ぶこ とで定義される。実数 $\mathbb{R}$ は，有理数の Cauchy 列 $\left\{q_{n}\right\}$ で, 収束率 $2^{-n}$ のもとする。 2 つの Cauchy 列に関す る等号 $={ }_{R}$ は自然に定義できるが，これによる同值類 から代表元を選ぶ操作はこの体系では出来ない。2つ の実数 $\left\{p_{n}\right\}$ と $\left\{q_{n}\right\}$ の和と積は次のように定義する：

$$
\begin{aligned}
& \left\{p_{n}\right\}+\left\{q_{n}\right\}=\left\{p_{n+1}+q_{n+1}\right\}, \\
& \left\{\mathrm{p}_{n}\right\} \cdot\left\{\mathrm{q}_{n}\right\}=\left\{\mathrm{p}_{n+m} \cdot \mathrm{q}_{n+m}\right\},
\end{aligned}
$$

ここで, $m$ は $\max \left(\left|p_{0}\right|,\left|q_{0}\right|\right)+1 \leq 2^{m-1}$ となる最小の自 然数とする。以上の定義のもとで， $(\mathbb{R},+, \cdot,<,=)$ が アルキメデス順序体になることが $\mathbf{R C A}_{0}$ で証明され る。
実数列は関数 $r: \mathbb{N} \times \mathbb{N} \rightarrow Q$ Q゙あって, $r_{n}(m)=r$ $(n, m)$ で定まる各 $r_{n}$ が実数になるものとする。区間 縮小法の原理は $\mathbf{R C A}_{0}$ で成り立つ。連続関数 $f: \mathbb{R} \rightarrow$ $\mathbb{R}$ は, $\forall x(p<x<q \rightarrow r \leq f(x) \leq s)$ を満たす 4 つの有理 数 $(p, q, r, s)$ の集合で定義する。すると, $\mathbf{R C A}_{0}$ で中 間值の定理が証明できる。その他, 代数学の基本定理 ([12]) や，(可算）アーベル群の基本定理や可算体を 包含する代数閉体の存在が $\mathbf{R C A}_{0}$ の定理となる。

体系 $\mathbf{W K L}_{0}$ は， $\mathbf{R C A}_{0}$ に “無限個の頂点を持つ 2 進 木は無限長の道（path）をもつ”という弱 König の補 題を公理として加えたものである。この体系は，算術 的論理式 (あるいは，その前に $\exists ! X$ を付けた式) の証 明可能性に関しては $\mathbf{R C A}_{0}$ と同等であり (後述), 有限 還元性も成り立つ。 $\mathbf{R C A}_{0}$ 上で, $\mathbf{W K L}_{0}$ と同值になる 定理の例としては, Heine-Borel の定理, Brouwer の 不動点定理，可分 Banach 空間の Hahn-Banach の定 理, 可分コンパクト群の Haar 測度の存在, 可算可換環 の素イデアルの存在などがある。

体系 $\mathbf{A C A}_{0}$ は，算術的論理式に関する帰納法と内包 公理によって特徴付けられ, 算術的内包公理の体系と 呼ばれる。 $\mathbf{A C A}_{0}$ の算術的定理は PA の定理と一致 し，有限還元性はもはや成立しない。これと同值な定 理には, Bolzano-Weierstrass の定理, Arzela-Ascoli の補題, 可算ベクトル空間の基底の存在, 一般の König の補題，可算可換環の極大イデアルの存在など がある。

体系 $\mathbf{A T R}_{0}$ は，算術的内包公理を超限回繰り返して 得られる集合の存在を主張する算術的超限再帰の公理 で特徵付けられる。この体系及び $\prod_{1}^{1}-\mathrm{CA}_{0}$ を必要とす る定理は, 集合論に関するものが多く, 普通の解析学 や代数学の定理は少ない。 $\prod_{1}^{1}-\mathrm{CA}_{0}$ の無矛盾性は竹内 外史によって証明されている。また，以上の 5 分類に 当てはまらない定理の例として, Hilbert の基底定理 (ACA $\mathbf{A}_{0}$ で証明可)，コンパクト空間の Borel 測度の可 算加法性 $\left(\mathbf{W K L}_{0}\right.$ で証明可)などもある。詳細は, [6], [10］を参照。

\section{$5 \mathrm{WKL}_{0}$ の自己埋め込み定理と超準解析}

$\mathrm{WKL}_{0}$ のモデルがもつ面白い性質のいくつかはか なり昔から知られていた。例えば, $(\omega, S)$ を $\mathrm{WKL}_{0}$ の モデルとすれば, $X \in S$ が存在し, $S^{\prime}=\{\{m:(m, n) \epsilon$ $X\}: n \in \omega\}$ は $S$ の真部分集合であって, $\left(\omega, S^{\prime}\right)$ は再 び $\mathrm{WKL}_{0}$ のモデルになる。この節では, $\mathrm{WKL}_{0}$ の可算 
モデルに新しい特徵付けを与える自己埋め込み定理と その超準解析への応用について述べる。

$\mathfrak{A l}=(M, S)$ を 2 階算術の構造とする。 $I$ を $M$ の始 切片（接頭部）として, $S\lceil I=\{X \cap I: X \in S\}$ そして $\mathfrak{H}\lceil I=(I, S\lceil I)$ とおく。次が自己埋め込み定理である。

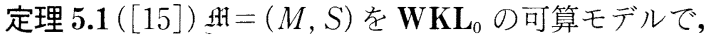
$\mathrm{M} \neq \omega$ とする。このとき, 我の真なる始切片 $\mathfrak{A} 「 I$ で, 此と同型になるものが存在する。

1970 年代半ばに H. Friedman は 1 階の Peano 算 術のモデルに対して,自己埋め込み定理を証明した。そ の後 Ressayre らによって，この結果は Peano 算術の 部分体系に一般化され, さらにそれを 2 階算術に拡張 したのが上の結果である。証明の骨組みは back-andforth 論法である。尚, $\mathbf{R C A}_{0}$ の一般のモデルについて は，自己埋め込みができないこともわかっている。

さて, $\mathfrak{H}=(M, S)$ を $\mathbf{W K L}_{0}$ の任意の可算非 $\omega$ モデ ルとする。上の定理から，䖽は自分自身に同型な始切 片をもつている。そもそも姐とその始切片は同型なの だから，両者の立場を入れ替えてみれば，然は自らと 同型な拡大 $* \mathrm{HA}^{*}=\left({ }^{*} M,{ }^{*} S\right)$ をもつことになる。この * 期を使えば，超準解析の議論が $\mathrm{WKL}_{0}$ でできる。

$\mathfrak{H}=(M, S)$ における実数 $a$ は, $S$ に属する集合であ る。従って， $a$ は， ${ }^{*} S$ 亿属する集合* $a$ の始切片 ${ }^{*} a\lceil M$ になる。ここで， *aは*册に扔いて有界にとることが できるので，*M の元でコードすることもできる。い ま, $\mathfrak{H}=(M, S)$ において, $[0,1]$ 上の連続関数 $f$ が与

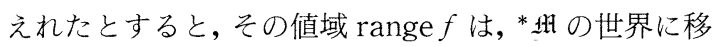
すと有限個の有理数の集まりのように扱うことができ る。従って，その中の最大元 * $a$ を見つけることがで き, その始切片 * $a\lceil M$ が連続関数 $f$ の最大值になる。 こうした論法を用いて, 常微分方程式の解の存在に関 する Cauchy-Peano の定理 ([16]) や可分コンパクト 群上の Haar 測度の存在 ([17]) が $\mathbf{W K L}_{0}$ で証明され る。尚, これらの定理に $\mathrm{WKL}_{0}$ が必要であることもわ かっている。

\section{Tree forcing と $\mathrm{WKL}_{0}$ の保存性}

木の集合上の包含関係による強制法は, Jockusch

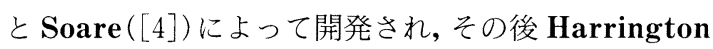
が $\mathrm{WKL}_{0}$ のモデルを構成するのに応用して広く知ら
れるようになった。ここでは, Harrington の証明の概 略と, その後の発展について述べる。

$\mathrm{Al}=(M, S)$ を $\mathbf{R C A}_{0}$ の可算モデルとする。 $\mathrm{T}_{\text {出 }}=\left\{T \in S:\right.$ 科 $=T \subseteq 2^{<X}$ は無限木\}.

とおき，これに $\left\{\left\{T^{\prime} \in \mathrm{T}_{\text {Ht }}: T^{\prime} \subseteq T\right\}: T \in \mathrm{T}_{\text {HH }}\right\}$ を開

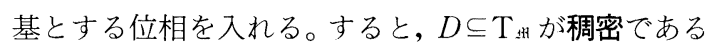

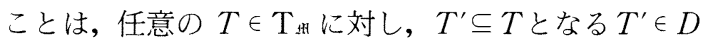

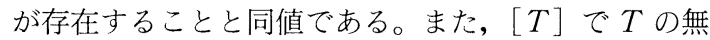

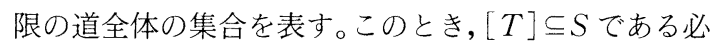
要はない。

集合 $G \subseteq M$ が HA-generic であるとは，fH で定義可 能な任意の稠密集合 $D \subseteq T$ 圤に対して, $G \in[T]$ とな る $T \in D$ が存在することをいう。为で定義可能な集

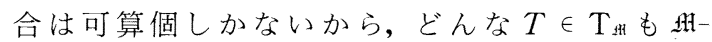
generic path $G$ をもつことがわかる。

いま $T \in \mathrm{T}_{\text {H }}$ を任意にとり，Gを $T$ の $\mathrm{At}_{\text {-generic }}$ path とする。 $G$ をパラメー夕に使って $\sum_{1}^{0}$ 式で定義で きる $\mathfrak{A -}$-有限集合は， $G$ の代わりに十分細い木 $T^{\prime} \supseteq G$ を使っても $\sum_{1}^{0}$ 式で定義できることから， $(M, S U$ $\{G\})$ が $\sum_{1}^{0}$ 㷌納法を成り立たせることがわかる。そこ で, $M \cup S \cup\{G\}$ をパラメータとして $\Delta_{1}^{0} て ゙$ 定義される 集合 $X \subseteq U$ の全体を $S_{G}$ として, $\mathfrak{H}[G]=\left(M, S_{G}\right)$ と おけば,

$$
\mathfrak{A H}[G] \models \mathbf{R C A}_{0} \wedge T \text { は無限長の道をもつ。 }
$$

この構成を繰り返すことにより， $\mathbf{R C A}_{0}$ のモデル $\mathfrak{H}=(M, S)$ に必要な道をす心゙て加えて $\mathbf{W} \mathbf{K L}_{0}$ のモデ ルをつくることができる。すなおち，次の定理を得る。

定理 6.1 (Harrington) $\mathfrak{A H}=(M, S)$ を $\mathbf{R C A}_{0}$ の可算モ デルとする。 $S \subseteq S^{\prime} \subseteq \mathbb{P}(M)$ となる $S^{\prime}$ が存在し， $(M$, $\left.S^{\prime}\right) \models \mathbf{W K L}_{0}$ 。

系 6.2 (Harrington) $\mathrm{WKL}_{0}$ で証明できる $\prod_{1}^{1}$ 文は, $\mathbf{R C A}_{0}$ でも証明できる。とくに算術命題に関して, $\mathbf{W K L}_{0}$ と $\mathbf{R C A}_{0}$ そして $\sum_{1}^{0} \mathbf{P A}$ (帰納法を $\sum_{1}^{0}-$ 式に制 限した Peano 算術）は互いに等しい。

上の系の直観的な意味は, 計算可能な世界に, コン パクト性を使った議論を持ち込んでも，証明できる算 術の定理は変わらないというものである。かつて Kreisel は, Gödel の構成的集合の議論から, 選択公理 を使って証明される算術の定理は選択公理を使わずに も証明できることを示したが, Harrington の結果はそ 
の計算可能バージョンといえるだろう。

Gödel-Kreisel の定理は，その後 Shoenfieldによっ て $\sum_{2}^{1}$-定理の保存性まで拡張されたので, Harrington の結果も解析的な命題に拡張させたいと思うのは自然 である。しかし, 弱 König の補題自体が $\sum_{1}^{1}$ で書ける

ので，素朴には 110 保存性が限界である。

まず，上の定理 6.1 を発展させ，次の結果を得た。

定理 6.3 ([14]) $\mathrm{H}=(M, \mathrm{~S})$ を $\mathbf{R C A}_{0}$ の可算モデルと する。 $\mathrm{S} \subseteq \mathrm{S}_{1}, \mathrm{~S} \subseteq \mathrm{S}_{2}$ が存在して, $\mathrm{S}=\mathrm{S}_{1} \cap \mathrm{S}_{2}$ かつ $(\mathrm{M}$, $\left.S_{1}\right) \models \mathbf{W K L}_{0}, \quad\left(M, S_{2}\right) \models \mathbf{W K L}_{0}$

この定理において, $\left(M, \mathrm{~S}_{1} \cup \mathrm{S}_{2}\right)$ が $\sum_{1}^{0}$ 㷌納法を成り 立たせるようにとれれば，以下が成立することがわか る :

予想 ([14]) $\varphi$ を算術的とし, $\forall X \exists ! Y$ $\varphi(\mathrm{X}, Y)$ で表せる命題は, $\mathbf{W K \mathbf { L } _ { 0 }}$ で証明で きれば， $\mathbf{R C A}_{0}$ でも証明できる。

この方針に沿って, 予想の解法に向けた努力が $\mathbf{T}$. Yamazaki や M. Fernandes らによってなされた。し かし,S.Simpson は, この方針の困難な点を指摘し, 代 わりに次を示した。

定理 6.4 ([7] $) \mathfrak{H}=(M, S)$ を $\mathbf{R C A}_{0}$ の可算モデルとす る。 $S \subseteq S_{1}, S \subseteq S_{2}$ が存在して, $S=S_{1} \cap S_{2}$ かつ $\left(M, S_{1}\right)$ $\vDash \mathbf{W K L}_{0}, \quad\left(\mathrm{M}, S_{2}\right) \models \mathbf{W K L}_{0}$, そして $\left(M, S_{1}\right)$ と $(M$, $\left.S_{2}\right)$ は $M \cup S$ をパラメータとする同じ論理式を成り立 たせる。

証明のポイントは, 汎用木の使用にある。 $T \in \mathrm{T}_{\mathrm{H}}$ が

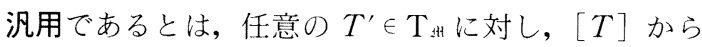
$\left[T^{\prime}\right]$ へ連続な埋め込みが存在することをいう。汎用 木の存在は, Pour-El と Kripkeの結果 ([5]) をヒン トに証明される。2つの汎用木が同じ論理式を force することは比較的簡単にわかるので, 汎用木を使って 構成すれば，同じ論理式を成り立たせる 2 つのモ゙ル $\left(M, S_{1}\right)$ と $\left(M, S_{2}\right)$ が得られる。上の定理から, 直ち に次を得る。

系 $6.5([7]) \varphi$ を算術的とし， $\forall X \exists ! Y \varphi(X, Y)$ で表 せる命題は, $\mathbf{W K L}_{0}$ で証明できれば, $\mathrm{RCA}_{0}$ でも証明で きる。
例えば，代数学の基本定理は，複素係数の多項式が 1 次式の積に一意に分解できるという主張と考えれ ば，上の系の形になる。代数学の基本定理には多くの 証明があるが，大概は解析的な手法でコンパクト性を 使うので，WKL $\mathrm{WL}_{0}$ で形式化できても，そのままでは $\mathbf{R C A}_{0}$ の証明にはならない。 $\mathbf{R C A}_{0}$ の直接の証明は, 多 項式の解を与えるアルゴリズムを具体的に示すものだ が,上の系を使えば,アルゴリズムを構成しないで, ア ルゴリズムの存在がいえることになる。

\section{7 実数の計算}

$\mathbf{R C A}_{0}$ において, 実数 $\mathrm{R}$ は, 有理数のCauchy 列 $\left\{q_{n}\right\}$ で, 収束率 $2^{-n}$ のものと定義された。このとき, $\mathbb{R}$ がアルキメデス順序体であることや,さらに実閉性 (多 項式に対する中間值の定理）が成り立つことも $\mathbf{R C A}_{0}$ で比較的容易に証明できる。しかし，これはRが実閉 体としてのすべての性質（実閉体の公理から導かれる 命題）を満たすことを保証するものではない。そもそ も R 2 階算術の述語であって集合ではないから,そ の性質を記述するにしても 2 階算術の枠内ではうまく 表現できないことがある。

具体的な例として, 連立一次方程式の解を GauBの 消去法等で求めることを考えてみよう。この計算では, ステップ毎に選ばれた係数が 0 になるか否かをチェッ クしなければならない。しかし，“ある実数 $X$ が $0 に$ なること”は集合 $X$ に関する $\Pi_{1}^{0}$ 述語であるから，任 意個の未知数を含む方程式に対してのアルゴリズムは $\mathbf{R C A}_{0}$ において実行が難しいばかりか, そもそも算術 的に記述できないものになってしまう。したがって, 行 列式の值が 0 でない行列は逆行列をもつことなども $\mathbf{R C A}_{0}$ では証明しにくい事実である。

そこで, S.G. Simpson と K. Tanakaは，Rにおけ る充足関係 $\mathrm{SAT}$ を Tarski の量化記号消去法の助け

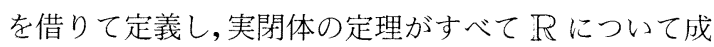
り立つことを 2 階算術の命題として表現し，それが $\mathbf{R C A}_{0}$ において証明できることを予想した。これに正 確な証明を与えたのが，論文 [19] である。また，こ の結果は, 論文 [18] において，体系内の超準的な長 さの命題にも拡張され，それによって, Hilbertの零点 定理などが $\mathbf{R C A}_{0}$ において証明できることがわかつ た。また， R Dedekind の切断を使って定義すると， 以上の結果は微妙に異なるものになることもわかって いる。 
最後に，このシンポジウムを企画し，筆者に標記題 目の講演と本論作成をお萀め下さった八杉満利子先生 に感謝する。

\section{参考文献}

[1] D. Hilbert and W. Ackermann, Grundzüge der theoretischen Logik, Springer-Verlag, 1928. 伊藤誠訳『記号論理の基礎』大阪教育図書, 1954 .

[2] Harvey Friedman, Some systems of second order arithmetic and their use, in Proc. of the $I$. C. M., Vancouver 1974, volume 1, pages 235242, Canadian Mathematical Congress, 1975.

[3] D. Hilbert and P. Bernays, Grundlagen der Mathematik I-II, Springer-Verlag, 1934-1939, 1968-1970 (2nd ed.). 吉田, 㴊野抄訳『数学の基 礎』シュプリンガー・フェアラーク東京, 1993.

[4] Carl G. Jockusch, Jr. and Robert I. Soare, $\Pi_{1}^{0}$ classes and degrees of theories, Trans. of the $A$. M. S., 173: 35-56, 1972.

[5] Marian Pour-El and Saul Kripke, Deductionpreserving "recursive isomorphisms" between theories, Fundamenta Mathematicae, 54(1): 141-163, 1967.

[6] Stephen Simpson, Subsystems of second order arithmetic, Springer-Verlag, 1999.

[7] Stephen G.Simpson, Kazuyuki Tanaka and Takeshi Yamazaki, Some conservation results on weak König's lemma, Ann. Pure Appl. Logic 118:87-114, 2002.

[8] 田中一之, “逆数学” と 2 階算術の証明論, 学会誌 『数学』 $42: 167-188,1990$.
[9] 田中一之, 逆数学と最近の数学基礎論, 学会誌『情 報処理』35(4)：329-340, 1994.

[10] 田中一之, 逆数学と 2 階算術, 河合文化教育研究 所, 1997.

[11] 田中一之 (編・監訳), 数学の基礎をめぐる論争, シュプリンガー・フェアラーク東京, 1999.

[12] 田中一之，数の体系と超準モデル，裳華房，2002.

[13] 田中一之, 鈴木登志雄共著, 数学のロジックと集合 論, 培風館, 2003 .

[14] Kazuyuki Tanaka, More on models of $\mathbf{W K L}_{0}$, hand-written notes, 1995. (A full exposition in Japanese is in R.I.M.S. Kokyuroku 976: 77--85, 1997.)

[15] Kazuyuki Tanaka, The self-embedding theorem of $\mathbf{W K L}_{0}$ and a non-standard method, Annals of Pure and Applied Logic, 84: 41-49, 1997.

[16] Kazuyuki Tanaka, Non-standard analysis in $\mathbf{W K L}_{0}$, Mathematical Logic Quarterly, 43 : 396400, 1997.

[17] Kazuyuki Tanaka and Takeshi Yamazaki, A non-standard construction of Haar measure and weak König's lemma, Journals of Symbolic Logic, 65 : 173-186, 2000.

[18] Nobuyuki Sakamoto and Kazuyuki Tanaka, The strong soundness theorem for real closed fields and Hilbert's Nullstellensatz in second order arithmetic, to appear in Archive for Math. Logic, 2003.

[19] Kazuyuki Tanaka and Takeshi Yamazaki, Manipulating the reals in $\mathbf{R} \mathbf{C A} \mathbf{A}_{0}$, in S. Simpson (ed.) Reverse Mathematics 2001, Lecture Notes in Logic, to appear. 